\title{
First record of Cassiopea andromeda (Scyphozoa: Rhizostomeae: Cassiopeidae) from the central Mediterranean Sea
}

\author{
PATRICK J. SCHEMBRI, ALAN DEIDUN AND PATRICK J. VELLA \\ Department of Biology, University of Malta, Msida MSD2080, Malta
}

\begin{abstract}
The occurrence of the scyphozoan Cassiopea andromeda is reported from the Maltese Islands, where a sizable aggregation was found in Marsamxett Harbour. This is the first record of this circumtropical species from the central Mediterranean Sea, hitherto known from the Levantine and Aegean basins. It is suggested that the most likely vector responsible for transporting this species to the Maltese Islands is shipping.
\end{abstract}

Keywords: Cnidaria, scyphomedusa, Malta, alien species, lessepsian invasion, range extension

Submitted 6 June 2009; accepted 26 June 2009

\section{INTRロDUCTIDN}

The so called 'upside-down jellyfish', Cassiopea andromeda (Forsskål, 1775), is not native to the Mediterranean, but was one of the first wave of lessepsian immigrants that entered the eastern Mediterranean through the Suez Canal. Galil et al. (1990) traced the history of its invasion of the Mediterranean to its presence in the Suez Canal in 1886, and the first record, off Cyprus (Maas, 1903). Cassiopea andromeda is well established in the Levantine and Aegean Seas, but was hitherto unknown west of the south-central Aegean (Galil et al., 1990; Çevik et al., 2006; Özgür \& Öztürk, 2008; Bayram Öztürk, personal communication, 2009).

\section{RESULTS AND DISCUSSIDN}

An aggregation of scyphomedusae of Cassiopea andromeda (Figure 1) was observed by one of us (P.J.V.) on 20 March 2009 close to the mouth of Marsamxett Harbour $\left(35^{\circ} 53^{\prime} 54.61^{\prime \prime} \mathrm{N} 14^{\circ} 30^{\prime} 21.13^{\prime \prime} \mathrm{E}\right)$, on the north-east coast of Malta, at depths of 3.5-6 m, on a muddy-sand bottom. The aggregation, consisting of about 50 individuals $3-11 \mathrm{~cm}$ in diameter, was observed again in the same location a month later, and a few individuals were still present at the end of May. The precise number of individuals could not be ascertained due to the very poor visibility. Although underwater photographs of the aggregation were taken, the results were not very satisfactory due to the amount of suspended particles in the water. Specimens were identified using the key in Galil et al. (1990). Cassiopea andromeda seems to prefer warm, well-lit, shallow and sheltered waters with muddy or fine sand

Corresponding author:

P.J. Schembri

Email: patrick.j.schembri@um.edu.mt bottoms, to permit exposure of the photosymbionts disposed in its oral arms (Verde \& McCloskey, 1998). The area in Marsamxett Harbour where the aggregation occurred conforms to this habitat type. It is worth noting that practically the only localities with shallow, sheltered, muddy habitats in the Maltese Islands are the main harbours, so there are few places where species such as Cassiopea can establish. No similar jellyfish, either in coloration or in behaviour, occur in the Maltese Islands. Local divers and fishermen, alert to the presence of jellyfish due to recurring 'blooms' (mostly of Pelagia noctiluca), have not reported aggregations of unusual species to local news media.

The genus Cassiopea has a wide circumtropical distribution in the western Atlantic and Indo-Pacific, including the Red Sea. Noting the taxonomic confusion in the genus, Holland et al. (2004) examined the global phylogeography and molecular systematics of the three currently recognized species: Cassiopea andromeda, C. frondosa, and C. xamachana. Their molecular phylogenetic results support identification of the Red Sea populations as C. andromeda. Although no specimens from the Mediterranean were studied by Holland et al. (2004), given the history of the introduction and spread of Cassiopea in the Mediterranean, it is reasonable to assume that the Mediterranean populations, including those reported here from the Maltese Islands, belong to C. andromeda sensu Holland et al. (2004). However, only molecular analysis of Mediterranean specimens will ascertain this, since Holland et al. (2004) found that in Hawaii there have been two independent introductions of different yet morphologically similar cryptic species from separate source populations.

At present one can only speculate as to how Cassiopea has arrived in the Maltese Islands. Although Cassiopea possesses pelagic larvae, surface currents in the region of Malta travel west to east. Potentially, larvae may reach the Maltese Islands from Sicily under certain conditions, but this species is not known from Italian waters (Anna Occhipinti Ambrogi, personal communication, 2009). Under the 


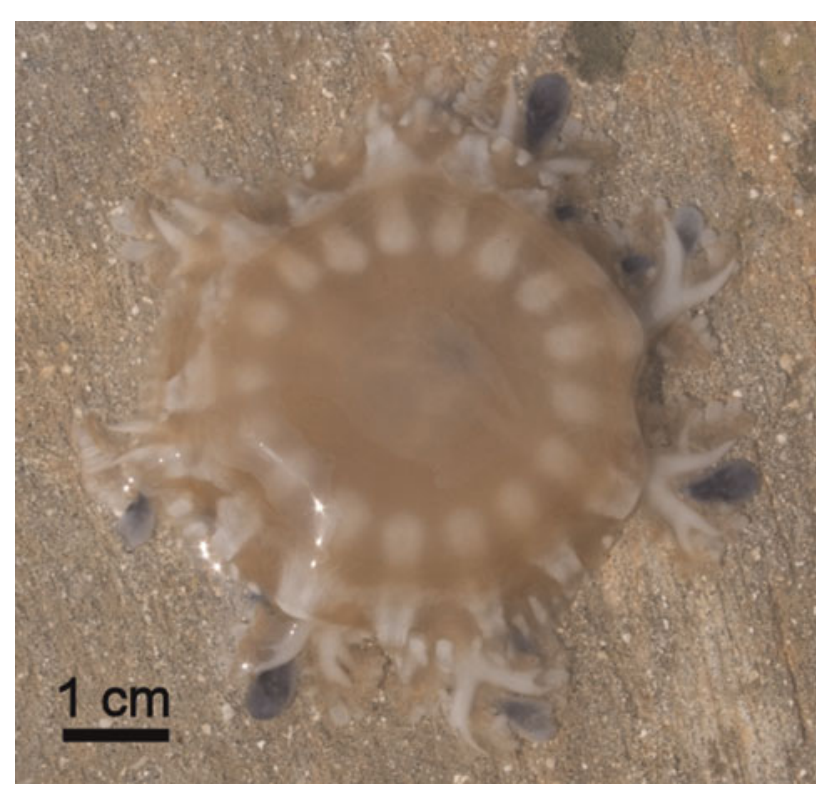

Fig. 1. Aboral view of a specimen of Cassiopea andromeda collected from Marsamxett Harbour, Malta on 20 March 2009, from a depth of $5 \mathrm{~m}$. (Image by P.J. Vella.)

circumstances, shipping seems to be the most likely vector either through the transport of larvae in ballast water, or of schyphistomae on hulls.

\section{ACKNDWLEDGEMENTS}

We are grateful to Professor Bayram Öztürk (University of Istanbul, Turkey) and Professor Anna Occhipinti Ambrogi (University of Pavia, Italy) for information on the distribution of Cassiopea, and to Professor Bella Galil (National Institute of Oceanography, Israel) and Ms Marija Sciberras (University of
Bangor, Wales) for making literature available to us. An earlier draft of this report was greatly improved by the comments of two anonymous referees.

\section{REFERENCES}

Cevik C., Erkol I.L. and Toklu B. (2006) A new record of an alien jellyfish from the Levantine coast of Turkey-Cassiopea andromeda (Forsskål, 1775) [Cnidaria: Scyphozoa: Rhizostomea]. Aquatic Invasions 1, $196-197$.

Galil B.S., Spanier E. and Ferguson W.W. (1990) The scyphomedusae of the Mediterranean coast of Israel, including two Lessepsian migrants new to the Mediterranean. Zoologische Mededelingen (Leiden) 64, 95-105.

Holland B.S., Dawson M.N., Crow G.L. and Hofmann D.K. (2004) Global phylogeography of Cassiopea (Scyphozoa: Rhizostomeae): molecular evidence for cryptic species and multiple invasions of the Hawaiian Islands. Marine Biology 145, 1119-1128.

Maas O. (1903) Die Scyphomedusen der Siboga-expedition. [Siboga-expeditie 11.] Leiden: E.J. Brill; viii + 91 pp. + plates I-XII.

Özgür E. and Öztürk B. (2008) A population of the alien jellyfish, Cassiopea andromeda (Forsskål, 1775) [Cnidaria: Scyphozoa: Rhizostomea] in the Ölüdeniz Lagoon, Turkey. Aquatic Invasions $3,423-428$

and

Verde E.A. and McCloskey L.R. (1998) Production, respiration, and photophysiology of the mangrove jellyfish Cassiopea xamachana symbiotic with zooxanthellae: effect of jellyfish size and season. Marine Ecology Progress Series 168, 147-162.

\section{Correspondence should be addressed to:}

P.J. Schembri

Department of Biology

University of Malta

Msida MSD2080, Malta

email: patrick.j.schembri@um.edu.mt 